\title{
Barriers to Placement of Spirometers in Clinics Affiliated with an Academic Medical Center
}

\author{
Victor O. Kolade \\ Department of Internal Medicine, College of Medicine, University of Tennessee, Chattanooga, USA. \\ Email: vkolade@gmail.com
}

Received November $14^{\text {th }}, 2011$; revised December $16^{\text {th }}, 2011$; accepted December $28^{\text {th }}, 2011$

\begin{abstract}
United States physician office visits for asthma have increased since 1989, and most of these visits are to primary care physicians. The National Institutes of Health has published guidelines for asthma diagnosis and management, implementation of which is expected to result in improved care and reduced costs. Compliance with asthma guidelines has been suboptimal, especially with spirometry recommendations, and more so in primary care clinics than in specialist clinics. Noncompliance has largely been attributed to physician and patient factors. This paper describes an experience with navigation of health system barriers to implementation of spirometry encountered at three primary care clinics affiliated with an internal medicine residency program. Included are perspectives and priorities of key individuals, systems issues related to institutions, and technical issues pertaining to spirometers. Navigation of ACGME core competencies is discussed.
\end{abstract}

Keywords: Spirometry; Medical Education; Asthma; Systems-Based Practice

\section{Introduction}

The prevalence of asthma has increased in the United States, affecting up to $8.2 \%$ of adults in 2009 [1]. The National Institutes of Health (NIH) guidelines recommend spirometry for diagnosis and monitoring of asthma, stating that office-based physicians who care for asthma patients should have access to it $[2,3]$.

Despite support from third-party payers and health maintenance organizations, compliance with the guidelines has been poor, especially with regard to spirometry $[4,5]$. Ready access to spirometric equipment can increase its use by primary care physicians from 19\% to $49 \%$, and the presence of a practice spirometer has been associated with use of spirometry in at least $75 \%$ of asthma patients [6]. Institution of spirometry in a medicine teaching clinic would exemplify faculty application of core competencies being taught to residents, such as systems-based practice [7]. Recent attempts to introduce office spirometry into three primary care clinics associated with an internal medicine residency program were met with unanticipated obstacles. The resulting experiences and suggested solutions to various challenges are described.

\section{Case Studies}

Early in September 2003, three of the major primary care sites associated with an academic Department of Medicine initiated quality improvement programs to increase adherence to national asthma guidelines. Meetings were held with physicians, office staff, and administrators to obtain buy-in and develop local institutional protocols to enhance compliance. One of the goals was to improve adherence to the recommendation for annual spirometry. All three clinics decided that having a spirometer on site would improve compliance.

One early discussion was with the Clinical Director in charge of the physician component of the three sites. He voiced three major concerns:

1) The service was already available. Respiratory Therapy could be paged and the therapist would come to the clinic (at least the clinic on-site in the teaching hospital) to perform the spirometry;

2) There might be a duplication of departmental effort. Spirometry was currently available through the pulmonary function laboratory run by the department's Pulmonary Division;

3) Cannibalization of other departmental revenue streams was possible. Performance of spirometry in the primary care centers might cut into the private practice billing of the Pulmonary Division.

\subsection{Response to Concern 1}

The plausibility of accessing spirometry for outpatients 
using hospital facilities was examined. It was found that the hospital had recently undergone a staff reduction for financial reasons, and Respiratory Therapy no longer had sufficient staff to serve the outpatient clinics.

\subsection{Response to Concern 2}

Spirometry was available through the pulmonary function lab, but primary care asthma patients were not receiving the service.

\subsection{Response to Concern 3}

From a financial perspective, these would be new services, and consequently, new billing opportunities. Hence revenues would be enhanced for the Department; the Pulmonary Division could not lose something it did not already possess.

In mid-October, with no progress having been made, compliance with asthma guidelines (including spirometry) was discussed in a departmental forum. The Chair graciously offered to purchase spirometers for the three sites with the understanding that a quality spirometer could be obtained for as little as $\$ 500$.

However, a key member of the Pulmonary Division was very negative concerning primary care physicians performing spirometry in their offices. He felt primary care physicians did not have the expertise required for provision of quality service; this opinion appears to be evidence-based [8]. The response? Though his concerns were legitimate, many primary care physicians were currently providing spirometry in their offices, consistent with national guidelines. Preliminary ordering information was thus obtained based on the Chair's offer. A purchase order was drafted with cost as the major criterion; three spirometers each costing approximately $\$ 500$ were requested.

Late in October, the purchase order had stalled in the Chair's office. The spirometers requested did not meet American Thoracic Society guidelines and were incapable of storing data for possible research [2,4]. After additional consultation, the ordering criterion became an emphasis on research. Discussions with vendors and departmental researchers lasted into December. In late December, a spirometer listing for about $\$ 2000$ was agreed upon. Though the vendor did not offer onsite service, a similar model was currently in use, and it was thought that available personnel could handle the technical details. Due to the dramatic cost increase, the financial agreement was revised such that the Chair would purchase a spirometer for one site, the Chief of the General Internal Medicine Division would purchase one for the second site, and hospital administration would be approached to obtain one for the hospital primary care clinic.

\subsection{Clinic 1}

This is the office where faculty members see their private patients; it is managed as a private practice. An order for a spirometer was placed in late December 2003, simultaneously with the order for Clinic 2 . The spirometer was invoiced through the private practice corporation and arrived in mid-January. The department information technology person was engaged to set the machine up, as it required a freestanding computer and a printer. The technical information enclosed with the machine was insufficient, and several calls to the company were necessary. Part of the problem was that the computers and printers were on a linked area network and there was no freestanding personal computer to which the attachment could be made.

A faculty member who had provided the technical specifications for the spirometer volunteered his research assistant to assist with learning the operation of the machine. Spirometers are high-technology items; like computers and cell phones, models are upgraded rapidly. Despite having the same model number (albeit with a different letter suffix) this machine was so different from the one the research assistant was using that it was a learning experience for her as well. It was soon realized that wrong parts had been shipped with the machine. Replacement parts were ordered, which arrived in February. The research assistant returned for instructional sessions, but the process stalled again when it was discovered the calibration syringe had not been included in the original shipment. A calibration syringe was then ordered.

The spirometer was ready for use in mid-February. Unfortunately, the initial set-up, focused on making the equipment functional, was on a computer in the central secretarial work area. The initial understanding based on earlier experience was that the spirometer would be freestanding and download to the computer on an as-needed basis. The new model required a permanent connection. While the spirometer was now functional, location was a problem. There had to be a private area with a dedicated computer where a patient could receive the spirometer test. The office was moving to a new location, so a suitable area was designated for the spirometer. The spirometer became fully functional the third week of March, six months after the process began.

\subsection{Clinic 2}

The second clinic is a freestanding, County Health Department clinic offering medical care to an underserved urban population. At the time, it was operating at a loss and undergoing drastic reorganization. A request for any expense would likely be denied; the purchase would need to be from an external source. 
The spirometer for Clinic 2 was purchased by the Division Chief using division funds, per the revised agreement with the Chair. It was ordered late December, simultaneously with Clinic 1 using the same vendor, but the purchase order was routed through university financial channels. These channels were slower than the private channels, so this spirometer arrived in February 2004, four weeks after delivery of the spirometer for Clinic 1. Lessons learned from setting-up the spirometer for Clinic 1 were applied, so that this spirometer arrived with the appropriate parts. The learning process at Clinic 1 enhanced the training of Clinic 2 staff, and this spirometer also became operational in March.

\subsection{Clinic 3}

The third clinic is a primary health care clinic run within a county hospital. Initial discussions during the summer of 2003 suggested that a purchase would not be required. An outreach clinic had just been closed for financial reasons, and that clinic had a "functioning" spirometer. The decision was made to move this spirometer to Clinic 3 for immediate use. However, equipment from the outreach clinic had traveled to different sites, making it logistically difficult to locate the equipment. The spirometer was ultimately found in storage in October and brought to the clinic-without supplies. The required supplies were ordered through usual hospital purchase procedures and finally arrived in early December.

Immediately there arose concerns from the clinic nursing staff concerning the possible increase in responsibilities. Many misgivings were allayed via attendance at nursing staff meetings.

In mid-December, the hospital infection control personnel performed a technical inspection. Their opinion was that the spirometer was serviceable, but would have to be disinfected after each use. This approach was deemed unworkable and was abandoned.

Discussion was then initiated with the administration of the clinic for the purchase of a spirometer. Letters of support were obtained from the Clinical Director and the Section Head for the Pulmonary Unit of the hospital. The Section Head had the following requirements for his support. He would not supply personnel, but would train a specific number of nurses who would be identified as the individuals to perform the spirometry. The number of nurses was to be limited to ensure quality control. The reports would be reviewed, interpreted and billed for by the Pulmonary Section Head or one of his staff. With this understanding and support, the clinic administrator was provided with specifics and purchase prices so that he could submit a request for the January 2004 budget cycle (a capital item of approximately \$2000). He however did not include the spirometer in his request, stating in February that he was overwhelmed by other requirements.
The next option was to approach the hospital Volunteer Board, which gave a yearly grant to support patient care. As part of the supporting documentation we were directed to discuss the specifics with the Pulmonary Unit and obtain its recommendations for a purchase that could be shared between the Pulmonary Clinic and Clinic 3 (the Pulmonary Clinic did not have a spirometer either). One of the pulmonary staff provided the name of a vendor and specifications, and a grant request for a $\$ 2000$ spirometer and $\$ 800$ for supplies was submitted for the March 1 granting deadline. Three weeks later, it became known that the proposal was not funded. Interestingly, a competing request had also been submitted by the Pulmonary Clinic for a $\$ 500$ spirometer and was approved for funding.

\subsection{Epilogue}

It took six months to place spirometers in two of three clinics. Sixty months later, Clinic 3 still did not have a functioning spirometer. The Pulmonary Clinic received its spirometer, but could not use it because the required software was not ordered with it.

\section{Discussion}

Numerous primary care physicians report not having spirometers in their offices, so many patients are sent to hospitals or other clinics, and some are referred to specialists for spirometry $[5,6]$. This experience identifies numerous barriers, sorted here into three groups.

\subsection{Decision Makers}

Concerns regarding provision of spirometers in the primary care setting included duplication of services, cannibalization of cash inflow for the Pulmonary Division, and budgetary and financial issues. The decision on which spirometer to order was complicated by competing priorities among cost, instrument quality and capability, and suitability for research. Some specialists, skeptical of the quality of service provided by primary care physiccians, opine that they are best suited to perform and interpret spirometry. While "turf" issues are not spoken of frequently, they do exist. These issues were addressed with reassurance and a cooperative sharing posture, utilizing interpersonal and communication skills.

Concern from nurses at Clinic 3 consisted of angst about increased workload and documentation. This was addressed at meetings with the nurses where clinic issues were discussed. The nurses expressed their concerns, and the place of this service in the quality of patient care was stressed. Their resistance was short-lived; nurses recognize spirometry as a key assessment tool in the care of asthma patients [9]. 


\subsection{Institutional}

While the cost of a spirometer was not large, it did not command sufficient priority to merit inclusion in the budget. We attempted to circumvent this problem by seeking alternate funding.

The spirometer initially proposed for use in Clinic 3 was outdated and unusable for infection control reasons. While it was attractive from a financial perspective, this approach was not viable. With the rapid evolution of technical and record-keeping requirements, use of older equipment should be viewed skeptically.

There existed different channels for funding an item: the university, the hospital, the Department of Medicine private practice, and grants from charitable organizations. These channels functioned at varying speeds, and could be stalled by inaction by key players occasioned by disagreement or failure to assign sufficient priority. Given the complexity of all the procurement channels, careful follow-up is essential.

Responsibility for billing on spirometry tests is important in institutional settings. This issue was clarified carefully.

\subsection{Technical Issues}

Spirometers are high-technology items marketed by a variety of vendors. New models and upgrades are released rapidly, leading to rapid obsolescence of equipment, parts and know-how. Purchase decisions are negatively influenced by uncertainty among purchase agents as to which item to buy, whether waiting will bring the price down, or whether a better machine will be available shortly. We experienced a steep learning curve due to complexity of the hardware and software. The spirometer is no longer a mechanical instrument alone but is integrated with a computer-and requires software [10]. It also may require connection to a linked area network and a network printer; these considerations may necessitate input from an information technology specialist.

Based on current spirometry guidelines, ease of infection control is one of several criteria commonly used to select an office spirometer [10].

\section{Conclusions}

Adherence to national guidelines requires system support. With ready access to the appropriate equipment, primary care providers are more likely to use spirometry in the diagnosis and management of asthma as recommended.

The partnership between providers and patients is one of the major focal points of the current asthma guidelines. This partnership needs to embrace healthcare systems and administration. Within smaller, self-contained units, decision-making may be easier. Within larger entities, competing units in the organization, multiple decision makers and complex interactions make the process more difficult. This report describes success in placing spirometers in two of the three target clinics. These experiences and recommendations are offered in the hope that, with foreknowledge of potential problems, others may negotiate the process more easily; application of the systems-based practice competency should be demonstrated by faculty in the same environment that it is taught to residents. Compliance with spirometry guidelines may be significantly hampered by logistic and organizational constraints.

\section{Acknowledgements}

I would like to acknowledge Charles O. Hershey, MD for his contributions to drafting earlier versions of this paper, Laurene M. Tumiel-Berhalter, Ph.D. for critical review, and Andrew Danzo for editorial assistance on earlier drafts of this paper.

\section{REFERENCES}

[1] Centers for Disease Control and Prevention, "Vital Signs: Asthma Prevalence, Disease Characteristics, and Self-Management Education-United States, 2001-2009," Morbidity and Mortality Weekly Report, Vol. 60, No. 17, 2011, pp. 547-552.

[2] National Asthma Education \& Prevention Program, "Expert Panel Report 2: Guidelines for the Diagnosis and Management of Asthma,” National Heart, Lung, and Blood Institute, Bethesda, 2003.

[3] National Asthma Education \& Prevention Program, “Expert Panel Report 3: Guidelines for the Diagnosis and Management of Asthma,” National Heart, Lung, and Blood Institute, Bethesda, 2007.

[4] E. N. Grant, J. N. Moy, K. Turner-Roan, S. R. Daugherty and K. B. Weiss, “Asthma Care Practices, Perceptions, and Beliefs of Chicago-Area Primary-Care Physicians. Chicago Asthma Surveillance Initiative Project Team,” Chest, Vol. 116, Supplement 2, 1999, pp. 145S-154S. doi:10.1378/chest.116.suppl_2.145S

[5] E. A. Blain and T. J. Craig, "The Use of Spirometry in a Primary Care Setting,” International Journal of General Medicine, Vol. 2, 2009, pp. 183-186.

[6] L. C. O’Dowd, D. Fife, T. Tenhave and R. A. Panettieri, "Attitudes of Physicians toward Objective Measures of Airway Function in Asthma," The American Journal of Medicine, Vol. 114, No. 5, 2003, pp. 391-396. doi:10.1016/S0002-9343(03)00007-X

[7] M. G. Stewart, “Core Competencies,” 2001. http://www.acgme.org/acWebsite/RRC_280/280_coreCo mp.asp

[8] T. Eaton, S. Withy, J. E. Garrett, J. Mercer, R. M. Whitlock and H. H. Rea, "Spirometry in Primary Care Practice: the Importance of Quality Assurance and the Impact of Spirometry Workshops," Chest, Vol. 116, No. 2, 1999, pp. 416-423. doi:10.1378/chest.116.2.416 
[9] B. Conner and A. Meng, "Pulmonary Function Testing in Asthma: Nursing Applications,” Nursing Clinics of North America, Vol. 38, No. 4, 2003, pp. 571-583. doi:10.1016/S0029-6465(03)00111-7
[10] J. Wanger and C. G. Irvin, "Office Spirometry: Equipment Selection and Training of Staff in the Private Practice Setting,” Journal of Asthma, Vol. 34, No. 2, 1997, pp. 93-104. doi:10.3109/02770909709075653 